\title{
Building a Social Network Around SoTL Through Digital Space
}

\author{
Shannon M. Sipes, Amy L. Minix, and Matt Barton
}

\begin{abstract}
In an effort to increase visibility of and access to the scholarship of teaching and learning (SoTL) work on one campus, a collaboration formed between a faculty developer, a librarian, and a media specialist within a center for teaching and learning (CTL). Building on the frameworks of community of practice, professional learning network, and social networking, the authors strategically leveraged digital space to begin building a social network of faculty members interested in SoTL. This article will address the theoretical foundation and practical implementation of five digital strategies: (a) website redesign; (b) social media presence; (c) blog series; (d) filmed faculty interview series; and (e) a dynamic database of institutional work.
\end{abstract}

Keywords: SoTL, collaboration, faculty development, technology, digital space

\section{Introduction}

Colleges began to shift focus from broad liberal education to highly specialized major programs in the 1930s and 1940s, and the unintentional result has been the delineation of disciplines. Because of this delineation, faculty must actively seek out opportunities for collabora- 
tion in order to avoid feeling isolated (Trust et al., 2017). This is particularly problematic at large universities composed of multiple schools and deep administrative structures. The separation of disciplines often results in a lack of communication among individual faculty members (both across schools and within departments), hindering collaboration, social learning, and professional growth. Therefore, faculty are often on their own to find ways to grow in their teaching practice (Trust et al., 2017; Williams et al., 2013).

Unlike faculty, students tend to have regular interaction with friends in other majors and take courses in other departments and schools. This allows them to be more widely connected than many faculty and raises their awareness of the isolation and categorization of faculty members. In a recent college newspaper article about silo mentality in academia, Adamucci (2016) shared the following quote from a senior level student:

I think that it would be helpful if professors looked into different things that are going on in different schools. I think that professors don't know exactly what is going on in different departments. I don't know if there is a lot of communication on that end.

Like students, centers for teaching and learning (CTLs) and librarians (perhaps more than other academic units) have the advantage of being centrally located, enabling exposure to faculty work across campus rather than in only one or two schools or departments (Otto, 2014). This provides a unique opportunity to "lead from the middle" in fostering connections among faculty members. The increasingly popular "lead from the middle" phrase originates from a model of higher education adopting a three-tier structure composed of the micro-social (i.e., individual instructors), the meso-social (i.e., instructors working collaboratively, CTLs, librarians, instructional technologists), and the macro-social (i.e., senior administrators) levels. The meso-level is characterized by individuals lacking formal institutional power. However, these are the very individuals uniquely positioned to 
act as informal leaders within teaching and learning and within the scholarship of teaching and learning (SoTL) specifically. Williams et al. (2013) suggest leveraging this position through three interrelated processes: (a) communication and dissemination of SoTL work on our campuses, (b) developing a social network among faculty, and (c) sustained support for faculty engaging in SoTL.

Sorcinelli et al. (2006; also in Beach et al., 2016) proposed a categorization of the field of educational development into five ages: age of the scholar, age of the teacher, age of the developer, age of the learner, and age of the network. Each of these categories reflects the objective of educational developers in their work with faculty members. In the first two categories, the focus was on the disciplinary expertise of faculty members as scholars and teachers. In the age of the developer, the focus shifted toward supporting faculty members collectively to improve student learning. The age of the network reflects the nature of educational development today. This stage takes a collaborative view of educational development in meeting faculty needs with CTLs working with libraries, instructional technologists, assessment offices, diversity offices, and others.

In their study, Beach et al. (2016) found technology centers and libraries were in the top three collaborations between CTLs and other campus units. Although CTLs currently address SoTL "to a slight extent," it is the first service CTL directors would add if given the opportunity or additional resources (Beach et al., 2016). SoTL is also an area addressed in the current professional library literature with a call to librarians to become more involved in SoTL on their campuses (Bradley, 2009).

Typically, CTLs provide services via hands-on workshops or individual consultations rather than web-based resources or electronic newsletters. Geographic and temporal factors have constrained opportunities to collaborate with colleagues in similar roles or expertise. Therefore, faculty collaborations often occur within the same discipline or within the same faculty learning community or other community of practice. Widespread access to the internet and social media is changing these 
interactions, affording new opportunities without the same constraints (Daniels, 2013; Robinson, 2008; Trust et al., 2017).

Although faculty tend to keep working long after their industry counterparts retire, resulting in an aging academy (Kaskie, 2017), the majority of new and future faculty members are millennials (born 19811996). This generation engages in the digital world at a much higher rate than previous generations (Vogels, 2019) and is more likely than older generations to engage in social networks via the digital world (Rainie, 2011). For millennials (aka: digital natives), technology and the networks they enable are integral parts of their lives:

Rather than being simply another generational change, the absorption of technology into the lives of this generation is so profound that it represents a discontinuity from previous generations, with changes in the way digital natives acquire information, think and learn. (Robinson, 2008, p. 68)

This literature has a direct impact on how librarians and CTLs deliver information, services, and resources (Robinson, 2008). CTLs are increasingly faced with a need to vary the delivery of programs, services, and resources to best support the range of users.

This article will outline five strategies initiated by a faculty developer, librarian, and media specialist to leverage digital space in building a social network around SoTL on one midwestern campus of a large state university. In developing the strategies, the authors utilized community of practice, professional learning networks, and social network theory as guiding theoretical frameworks.

\section{Guiding Frameworks}

Pataraia et al. (2015) acknowledge that "in the literature, the notions of communities of practice and networks are sometimes used inter- 
changeably" (p. 341). However, we propose they can better be thought of as a continuum of faculty engagement, where an individual may move from outsider to member of a social network to member of a community of practice with each category requiring an increase in commitment.

\section{Community of Practice}

Communities of practice (CoPs) are grounded in social learning among people who have a common interest. These groups are further defined by "three crucial characteristics: sustained mutual engagement in practice, pursuit of a joint enterprise, and a shared repertoire of resources, experiences, stories, and tools" (McKenna et al., 2016, p. 32). Because of the extended period of collaboration among members, CoPs are an effective way to advance faculty development, facilitate exchange of information between members, and transform teaching practice (Van Rensburg et al., 2016).

Although traditionally CoPs take the form of a faculty learning community (FLC) with in-person meetings among faculty members on one campus, CoPs can be found in virtual spaces as well (Bedford \& Rossow, 2017; Cohn et al., 2016; McKenna et al., 2016; Nistor et al., 2012). As with traditional CoPs, within virtual CoPs (vCoPs), "learning is focused on advancing the knowledge of the shared domain, which is nurtured by a common history of learning, shared practices and the commitment to negotiate, learn and develop ideas and resources together" (Macià \& García, 2016, p. 293).

Models of faculty change recognize that adoption of pedagogical approaches occur in stages, beginning with some form of awareness about the concept, followed by an interest in learning more (McKenna et al., 2016). Some faculty may not see themselves as ready for a CoP but may be interested in learning more about SoTL research. In contrast to a CoP or a vCoP, a professional learning network may be the most appropriate form of engagement for these individuals. 
Participation in a network provides access to a wide range of information flows that can be useful for obtaining resources, finding solutions or establishing dialogues in targeted or untargeted searches. The commitment required to participate in a community should be high and sustained, whereas participation in a network can be spontaneous, unpredictable, and serendipitous. (Macià \& García, 2016, p. 293)

\section{Professional Learning Networks}

Pataraia et al. (2015) define professional learning networks (PLNs) as "a group of people who can guide your learning, point you to learning opportunities, answer your questions, and give you the benefit of their own knowledge and experience" (p. 340). They often include people who offer feedback and new ideas, provide emotional support, or present opportunities for collaboration (Trust et al., 2017). Often the results of these interactions become embedded in one's teaching practice (Pataraia et al., 2015). Therefore, a PLN often serves as an informal vCoP, allowing academics to connect and engage around common interests that informally support their professional development (Trust et al., 2017).

Through these networks, faculty begin to feel less isolated (Williams et al., 2013) and become more likely to engage in their own SoTL work (Rienties \& Kinchin, 2014). Social networks are thought to provide four additional benefits to members: (a) increase access to materials, innovative practices, and experiences of other members; (b) influence professional development practices of members; (c) confirm members' social credentials through access to social capital; and (d) reinforce members' identity and recognition (Rienties \& Kinchin, 2014).

When investigating faculty involvement in PLNs, Trust et al. (2017) found the spaces in which faculty engaged in PLN activities digitally were not limited to social media sites but also included blogs, curation tools, newsletters, listservs, websites, and library databases. Types of engagement in these spaces also varies. Faculty may choose to utilize 
them to make connections, engage in conversation, follow specific individuals, locate knowledge, and/or curate resources. "This diversity highlights how PLNs can offer flexible, adaptable, and personalized learning experiences" (Trust et al., 2017, p. 5).

In order for a SoTL PLN to be successful, there needs to be a "critical mass of SoTL champions to allow social networking and crossfertilization of ideas" (Williams et al., 2013 p. 53). Experienced faculty members tend to have larger, stronger, and more diverse academic social networks than novice faculty members (Van Waes et al., 2015), suggesting that novice faculty may need an entry point prior to a PLN. Faculty must be aware not only of the concept of SoTL but also of others doing this kind of work before they can engage in a SoTL-based PLN.

\section{Social Networks}

Social networks designed uniquely for the academic audience, such as ResearchGate and Academia.edu, are referred to as academic social networking sites. The purpose of these sites is not only to connect researchers across geographic distance but to allow for easy access to research, often even prior to publication. Meishar-Tal and Pieterse (2017) found faculty who were active in academic social networking sites did so mostly to read others' research and share their own work, allowing them to belong to a peer community. Although interaction with other users is feasible on these sites, users typically do not engage in this activity. "Some scholars argue that academic social networks replicate, and in certain cases even improve, the experience of social activity at a conference by helping to create and expand researchers' professional networks" (Meishar-Tal \& Pieterse, 2017, p. 4).

Networking online among academics is not limited to academic social networking sites. Numerous Facebook groups serve as PLNs organized around not only discipline but academic identity as well. Technical Communication \& Rhetoric Scholars, Cross-Cultural Psychology News and LGBTQ Research and Researchers in Higher Education 
and Student Affairs are examples of Facebook-based PLNs organized around discipline, whereas Academic Mamas, Anti-Racist Mothers \& Scholars and NC Academic Mamas are organized around being a mother in academia.

Twitter is another platform that is increasingly utilized by academics to engage with other academics with similar interests and challenges. One of the advantages of Twitter is the ability to follow and retweet other users as well as view the following/followers of those one is interested in. This digital footprint facilitates the creation of a social network broader than one's own institution (Budge et al., 2016).

These social frameworks broaden the ways librarians and faculty developers can engage faculty in SoTL work. They enable increased communication and dissemination of SoTL work on campus, develop a social network among faculty clients, and enable sustained support for faculty engaging in SoTL (Williams et al., 2013) outside of the traditional framework of workshops and funding programs. By focusing on frameworks related to digital space, librarians and CTLs are no longer constrained by geographic or temporal location or monetary resources.

\section{Institutional Context}

Indiana University Bloomington (IUB) is a large, public, midwestern research university that is part of a statewide system composed of nine campuses in total. Each campus has its own administrative structure responsible for supporting the faculty members on that particular campus, including libraries and CTLs. The IUB campus provides 16 degree granting schools and colleges, composed of 2,456 instructional faculty, 33,429 undergraduate students, and 10,281 graduate students (Indiana University Research and Reporting, 2017). There are 11 libraries on campus and the CTL is physically located in the main library.

The CTL is made up of 15 full-time staff broken into four teams by broad areas of expertise (pedagogy, instructional technology, service- 
learning, and writing) and one center director. The pedagogy team has four full-time staff and three graduate students who provide not only support for all general teaching and learning requests but also departmental level curriculum and assessment support, graduate student professional development around teaching, diversity and inclusion initiatives, and SoTL.

The SoTL program consists of one full-time staff member who also serves as a general pedagogical consultant and one graduate student who provides 10 hours of support per week. In addition to the challenge created from staffing, the SoTL program underwent a change in leadership at the beginning of the 2017-2018 academic year from a formal program director to an interim director. Due to the timing of the leadership transition, the budget was inherited and partially allotted prior to new leadership. These challenges provided an opportunity to evaluate and refocus the SoTL program.

Two guiding goals were chosen for the 2017-2018 academic year:

1. Increase visibility of SoTL work on campus.

2. Increase accessibility to SoTL work for novice researchers.

One of the first tasks of the transition was for the interim SoTL director to take stock of current initiatives and resources. One of these resources was the unique skill set of the SoTL graduate student who was in the final year of a library and information science program. Another resource was the CTL media specialist. These people resources required no additional monetary funding or time but simply a shift in project focus to better utilize the unique individual skill sets into a collaborative team.

Based on the challenges and people resources, the chosen approach to meet the guiding goals was to leverage digital space in an effort to build a social network of faculty interested in SoTL on campus. Five specific strategies were chosen based on web analytics of the CTL website, a review of CTL websites at other institutions, and a needs analysis. These strategies are as follows: 
1. addition of regular SoTL blogs in the CTL-wide series,

2. redesigning the SoTL pages on the CTL website,

3. creating Twitter handle and developing social media presence,

4. creating faculty spotlight videos specific to SoTL, and

5. transforming a static institutional SoTL bibliography into a dynamic institutional database of SoTL work.

\section{Digital Strategies}

\section{Strategy 1: SoTL Blog Series}

Many CTLs use blogs as one of multiple client communication strategies, a practice supported in empirical literature (Macià \& García, 2016; McKenna et al., 2016). For example, the Center for Research on Learning and Teaching blog at University of Michigan launched in August 2012, SoTL Advocate at Illinois State University in October 2014, and The SoTL Guide Blog at University of Calgary in January 2016. Although the larger IUB CTL launched a blog in March 2016, the SoTL program did not begin blogging until almost a year later in May 2017 when this strategy was chosen as one way to make SoTL more accessible to novice SoTL researchers at the university.

The content of the blog posts over the first year was aimed at unpacking SoTL jargon and exposing faculty readers to activities involved in SoTL work they may already be doing in their courses. At the time of this article, select SoTL blog titles have included "What Is SoTL?" "Moving from Scholarly Teacher to SoTL Researcher," "Multipurpose Course Activities for SoTL Data," "But, I Don't Know HOW to Do SoTL Research," "Do I Really Need IRB Approval for My SoTL Project?" and "Do You Know Who's Doing SoTL Work at IUB?"

Each blog post is written by the SoTL director in an informal, first person voice to convey a personal and conversational tone. Publication occurs the second week of each month on the larger CTL blog as part of the initial strategy to build a digital presence and consistency 
in voice and name recognition within the program. Unsurprisingly, novice faculty members tend to seek out networking with experts because of their experience and expertise (Van Waes et al., 2015), and this strategy clearly identifies a starting place for these faculty to become connected. At the end of each blog post are links to additional programming that faculty can register to attend or links to resources that provide more information on the topic of the post. The blog is structured to allow readers to comment on individual blog posts, encouraging dialogue and networking. However, this feature has been rarely utilized.

As of August 2018, Google analytic data on the blog series indicate the average number of views $(M=95)$ across the 17 SoTL focused blog posts is higher than the average number of views $(M=68)$ across the CTL blog overall. With 10,357 views of 129 total CTL posts since March 2016, the 1,613 views on SoTL topics account for $16 \%$ of readership overall. This provides an early indication that the SoTL focused blogs are of interest to readers.

\section{Strategy 2: Web Redesign}

The SoTL program has had a section on the larger CTL website since the 2010-2011 academic year. Despite a university-wide system update in January 2017, the content on the SoTL pages remained static, outdated, and functioned as an internal archive for program staff rather than a resource for IUB faculty. Content on these pages included (a) a historical list of past SoTL events, (b) full proposals from funded SoTL grants, (c) a pdf of citations compiled into an institutional SoTL bibliography, and (d) sparse resource page summarizing two other campus support offices. The SoTL director determined the current content did not meet the guiding program goals and approached the media specialist to overhaul the SoTL portion of the larger CTL website.

This overhaul began with an examination of web analytics comparing the SoTL pages to the larger CTL site. Data on the number of page views, time spent on each page, and web traffic patterns suggested 
that users did not find the site helpful. At the same time, a comparison was conducted between the IUB CTL pages (including SoTL) and the CTL websites of seven institutions with similar CTL structures to determine similarities and difference in the types of information available to users.

In order to hear from the client voice, faculty members of the SoTL advisory board were asked to complete a user survey to examine the utility of current features and suggest additional features they would like to see added to the SoTL program pages. The advisory board was chosen as a purposeful sample of campus faculty due to their interest and knowledge of the current website as well as the time investment required to complete the user survey.

The results of this survey indicated that the advisory board could not live without the list of external speakers brought to campus to give keynote talks or the information on SoTL funding opportunities. These are the two aspects of the SoTL program that are most well established and visible to the campus, so this response was not unexpected. However, the advisory board did not feel the SoTL time line or bibliography web pages were critical. The SoTL time line functions more as a history of the SoTL program on campus and is almost a decade out of date. The bibliography web page was a static series of pdf files archiving IUB faculty publications around SoTL. Identification of these items was also not unexpected.

An unexpected finding of the survey was difficulty navigating the larger CTL website. Advisory board members stated the navigation itself was well labeled, but there was some reported difficulty distinguishing between the SoTL program web pages and the CTL general web pages. It was unclear to the advisory board members where the distinction between SoTL and broader CTL services fell.

When asked what additional types of information they would like to see on the website, advisory board members responded with MORE: more resources for IUB faculty interested in SoTL work, less text and more visual information, opportunities to engage in SoTL 
beyond campus, and increased ability to find and view the work of other IUB faculty. The three quotes from advisory board members below best represent the responses.

I don't get a good picture of SoTL's current goals and practices from the website. I can see past work, I can see that there is some small funding opportunities, and a couple of events per year. If I were interested in getting more involved, I would have a hard time figuring out what I could do. (Faculty A)

I think it is rather "dry." Perhaps it could have some stories, video, pictures of faculty with students, or faculty presenting SoTL stuff at conferences. (Faculty B)

In general, these pages come across as a record of SoTL projects that have been funded/completed at IUB rather than a resource for people wanting to do SoTL research. If I'm the intended audience for these pages, in general, I'd like to see lots more resources on the SoTL Resources page, and to have those resources highlighted. If I wanted to learn what SoTL was or how to do it, this page wouldn't necessarily help me find out where to do that. (Faculty C)

The website redesign addressed this feedback by overhauling the SoTL site including the following changes:

1. clarifying the mission and goals of the SoTL program;

2. providing links to SoTL support by campus units outside of the CTL and organized by project stage;

3. transitioning the static institutional bibliography to a dynamic database;

4. featuring SoTL activity by IUB faculty; and

5. outlining ways faculty can connect with the IUB SoTL program online, on-campus, regionally, and beyond. 
Early (August 2018) Google analytic data on the redesigned website suggest users find it more helpful than the old website. Users are spending more time on both the home page and resource page, both of which have expanded content. Viewers are spending less time on the featured activity and finding SoTL pages, suggesting the new focus allows users to find what they need more quickly. (For a breakdown on number of views and time spent per page, see Table 1.)

\section{Strategy 3: Social Media Presence}

One comment on the website user survey that could not be easily addressed through the website redesign alone was an expressed interest to crowdsource SoTL events across campus.

I'd like to see an aggregator for SOTL-related or inspired events hosted through the individual schools or departments, in addition to

Table 1. Comparison of SoTL Web Page User Traffic from January $2017-$ September 2018

\begin{tabular}{|c|c|c|}
\hline Page content & $\begin{array}{c}\text { Old page } \\
\text { (January 2017-April 2018) }\end{array}$ & $\begin{array}{c}\text { Redesigned page } \\
\text { (March 2018-September 2018) }\end{array}$ \\
\hline \multicolumn{3}{|l|}{ SoTL home } \\
\hline Total views & 313 & 132 \\
\hline Avg. time spent & $2 \min 2 s$ & $3 \min 37 s$ \\
\hline Avg. views per month & 22 & 19 \\
\hline \multicolumn{3}{|l|}{ Resources } \\
\hline Total views & 123 & 71 \\
\hline Avg. time spent & $3 \min 13 s$ & $3 \min 33 s$ \\
\hline Avg. views per month & 9 & 10 \\
\hline \multicolumn{3}{|l|}{ Find SoTL } \\
\hline Total views & 36 & 16 \\
\hline Avg. time spent & $1 \mathrm{~min} 56 \mathrm{~s}$ & $2 \min 46 s$ \\
\hline Avg. views per month & 3 & 2 \\
\hline \multicolumn{3}{|l|}{ Featured activity } \\
\hline Total views & 19 & 4 \\
\hline Avg. time spent & $4 \min 32 s$ & $1 \mathrm{~min} 10 \mathrm{~s}$ \\
\hline Avg. views per month & 1 & 0 \\
\hline
\end{tabular}


CITL-sponsored SOTL work. This might foster more community. (Faculty D)

The media specialist and SoTL director reflected on this statement and determined the best approach would be the creation of a Twitter handle to most easily allow community input. The larger CTL has both a Facebook and Twitter presence, and social media easily allows users to share information instantly.

The rise of social media has most recently evolved the ways in which academics engage in scholarship, providing a new way of conducting outreach, engagement, and education (Daniels, 2013; Mackenzie \& Martin, 2016). Although CTLs and librarians are aware of many opportunities across campus, it is impossible to remain aware of all of the professional development opportunities available at any given time. Establishing a Twitter presence enables individual faculty to share opportunities using the IUB_SoTL tag, inviting them into the SoTL social network on campus. In addition to a collective sharing of SoTL work, the Twitter presence allows the program to live tweet from events, easily share SoTL conversations occurring outside of campus, and make visible the network of individuals engaged in SoTL work through followers.

Twitter analytics (September 2, 2018) provide a number of useful initial data points. IUB_SoTL at the time had 129 followers. The majority of these followers were female (66\%) and from IUB (25\%). Ninetysix percent indicated an interest in science news. These early data suggest that female faculty with an interest in STEM education represent the majority of our audience. The first 99 posts made since the creation of the account received an average of approximately 7,800 views per month.

\section{Strategy 4: SoTL Faculty Spotlights}

Although the blog posts represent the voice of one SoTL expert on campus, there are many SoTL experts on campus. Just as CTLs and li- 
brarians can lead from the middle, individual faculty members may also operate at the meso-level (Rienties \& Kinchin, 2014). Leveraging a broader CTL strategy, a series of structured interviews with faculty members who are active in SoTL were recorded to create spotlight videos in an effort to increase visibility of this campus expertise.

The concept of an expert spotlight video is not novel (Auburn Biggio Center, n.d.; Center for Engaged Learning, n.d.; IUB CITL, n.d.), but the SoTL faculty spotlights are unique in two ways. First, the SoTL faculty spotlights represent IUB faculty members to highlight SoTL expertise on campus rather than international SoTL experts located off campus. Second, the story line for the videos highlights the faculty member's trajectory from novice to expert SoTL researcher rather than a SoTL project.

As with the blog series, the spotlights convey an informal, conversational voice in an effort to create a feeling of approachability in viewers. Although the spotlights are not scripted, interviewees are asked to review the interview questions prior to recording and encouraged to rehearse their natural responses to provide succinct answers no longer than 2 minutes. While interviews took approximately 30 minutes to record, they were edited to a final length of 7 to 10 minutes to optimize views (Bligh, 2000; Svinicki \& McKeachie, 2014).

In 2017, the SoTL program introduced the dimensions of activities related to teaching (DART) model (Kern et al., 2015) to help faculty members better understand the types of activities that constitute SoTL. For the spotlights, faculty were asked to indicate where they fell on the model when they first began their career and where they feel they now fall. When editing the interviews, a graphic of the DART model (Kern et al., 2015) was placed behind the speaker, and as they referred to a quadrant in the model, it was highlighted on the screen. Providing viewers with a visual aid when presenting new information reduces the cognitive load of the viewer and reinforces the new information (Costley \& Lange, 2017; Mayer, 2009).

Videos were added to the broader CTLs YouTube page under a SoTL specific playlist and linked on the SoTL website. When rolling out 
a new spotlight video, a blog with additional interview information that did not make the final video cut was provided. It was then shared via SoTL and CTL social media accounts as well as the faculty interviewee's personal and departmental social media accounts. Connecting the video strategy with the previous three strategies (i.e. blog, website redesign, and social media presence) created additional networks and provides more points of entry into the SoTL social network for outsiders and members.

YouTube analytics of the first three spotlights indicate the videos received most of the views within the first week of rolling out the spotlight. These videos received an average of 45 viewsas of September 2018. The overwhelming majority of viewers were internal to the IU system (range $80 \%-88 \%$ ), which is the target demographic. These limited initial data show promise and will continue to be evaluated as more videos and time are added.

\section{Strategy 5: Institutional SoTL Database}

The SoTL program maintains an institutional bibliography of SoTL work conducted on campus (briefly mentioned under "Strategy 2: Web Redesign"). Until the 2017-2018 academic year, the bibliography was composed of APA formatted citations of IUB faculty SoTL publications that were collectively compiled into a static pdf and published on the SoTL website. The pdf was split into five documents, alphabetically grouped by first author, and ranged from five to seven pages long. Keeping the bibliography current required the SoTL graduate student to send an email to the IUB SoTL listserv asking members to submit any new work via email reply. The graduate student would then update a Word document, save it as a pdf, and publish the bibliography on the website.

In order to utilize the bibliography, the individual visiting the website needed to know the last name of the first author cited on the work. Locating SoTL work for a faculty member listed as second or third author was feasible only if the first author was also known. Highly 
active SoTL researchers included in the bibliography were given a (often broken) link to their personal cv rather than individual citations for each artifact.

Although publications can foster networking among faculty and be instrumental in spreading SoTL work as a campus norm (Williams et al., 2013), they must be accessible. Mackenzie and Martin (2016) suggest that scholarly practice can be transformed when three digital elements converge: (a) digitization of content, (b) open networking (peers and content), and (c) shared values (sharing of ideas, materials, data, discussions). One of the strengths of academic librarians focused on information science is connecting users to the resources they need, designing information repositories to store and organize information, and connecting users to scholarly or reputable sources (McVeigh, 2011). As a library and information science master's student, the SoTL graduate assistant was uniquely positioned to convert the archival institutional bibliography into a dynamic database.

First, each citation included in the bibliography was transformed into a standardized and encoded machine-readable format using extensible markup language $(X M L)$. Then these $X M L$ citations were archived to create a database within IUB's web content management system (WCMS). Once the archive was complete, the third step was to develop an outward facing interface via JavaScript to pass archived information from WCMS to the user. The final SoTL database interface enables users to search for SoTL work conducted on campus by discipline, author, year, format (i.e., book, article), or keyword. The new interface also provides a direct link to the cited work when that work is open access.

In addition to drastically improving the functionality of the bibliography through the creation of the dynamic database, functionality of database maintenance was also increased. Rather than emailing a listserv and transcribing the responses on an annual or semester basis, faculty may now submit new citations, link to open source materials, and upload unpublished work or datasets via a Qualtrics form available on the database web page at any time. These submissions can 
then be included in the database each month rather than each semester or year.

The static bibliography page received 45 views between January 11, 2017, and March 7, 2018. Between March 7, 2018, and September 2018, the database page received 112 page views. In addition to an increase in views, the average session duration has diminished from 2 minutes 4 seconds to 1 minute 3 seconds. This suggests that users are finding the desired information among the 653 artifacts in the database much more quickly. Usage has been consistent since publishing, approximately half of the views come from IUB $(n=51)$ suggesting members of the IUB community are interested in their colleagues' work.

\section{Conclusion}

The initial data indicate that all five of the digital strategies (website redesign, social media presence, blog series, filmed faculty interview series, and a dynamic database of institutional work) are being used by our target audience. This suggests the collaboration between a faculty developer, a librarian, and a media specialist within a CTL to develop digital strategies in an effort to increase visibility of and access to SoTL work on one campus was successful. These strategies appear to enhance communication around SoTL topics with CTL clients. It is too early to tell if the strategies result in on-campus social networks of faculty interested in SoTL.

Williams et al. (2013) and Van Waes et al. (2015) acknowledge the scarcity of empirical work investigating the most effective tactics for building social networks and communication around SoTL. Pataraia et al. (2015) explain that "extant research in this area has largely focused on examination of networks [CoPs] in the context of established, formalized networks and within teaching in compulsory education" and identify gaps left in the literature, including "limited understanding of bottom-up network processes (for instance, learning and advice- 
seeking) and of overall network value/benefits for professional development from the standpoint of individuals" (p. 337).

Additional web analytics and social network analysis will be used to measure the impact of these digital strategies in fostering faculty network around SoTL once the strategies have been live for a full academic year. The combination of these techniques will allow us to measure usage of the digital resources as well as facilitate analysis of the informal relationships among faculty (Rienties \& Kinchin, 2014; Royal et al., 2014). The initial results are positive enough to promote and continue implementation and expansion of these services without waiting for more detailed empirical support.

\section{Biographies}

Shannon M. Sipes is Director of the SoTL program and a Lead Instructional Consultant within the Center for Innovative Teaching and Learning at Indiana University. In this role, she provides support to faculty in their SoTL projects as well as in their curriculum design and teaching work. As a pragmatist, Shannon's research interests include examining the impact of various pedagogical approaches on student learning and assisting others in the design of their SoTL work. The way a question is answered is more interesting to her than the topic of the question itself. She earned her $\mathrm{PhD}$ in Curriculum and Instruction with a focus on Higher Education from Indiana State University.

Amy L. Minix is a Visiting Assistant Librarian in the Sciences Library at Indiana University Bloomington. In her role, she provides a variety of services to psychological science faculty such as information literacy support, data services, class reserves, and research assistance. During the work of this manuscript, she was the graduate assistant for the SoTL program.

Matt Barton is a Media Specialist and Instructional Consultant at Indiana University Bloomington's Center for Innovative Teaching and 
Learning. He assists faculty in translating traditional lecture material to active learning activities and instructional video for more dynamic f2f, hybrid, and flipped classrooms. As Media Specialist, Matt directs and assists colleagues in their videographic and graphic design needs. Matt also acts as the webmaster and strategist for the center's online content and marketing. Matt graduated from Purdue's Computer Graphic Technology program with a focus in digital animation.

\section{Acknowledgments}

The authors would like to thank Clinton McKay for providing individual training and support to Amy Minix during the development of the SoTL database. He was instrumental in helping her to develop the coding skills needed to complete this portion of the project.

\section{References}

Adamucci, S. (2016, October 29). Silo mentality in higher education plays a role at Ithaca College. The Ithacan. https://theithacan.org/news/ silo-mentality-in-higher-education-plays-a-role-at-ithaca-college/

Auburn Biggio Center. (n.d.). Home. YouTube. https://www.youtube.com/ user/AuburnBiggioCenter

Beach, A. L., Sorcinelli, M. D., Austin, A. E., \& Rivard, J. K. (2016). Faculty development in the age of evidence: Current practices, future imperatives. Stylus Publishing.

Bedford, L. A., \& Rossow, K. A. (2017). Facilitating professional learning communities among higher education faculty: The Walden Junto model. Online Journal of Distance Learning Administration, 20(2), 1-12.

Bligh, D. A. (2000). What's the use of lectures? Jossey-Bass.

Bradley, C. (2009). The scholarship of teaching and learning: Opportunities for librarians. C\&RL News, 70(5), 276-278. https://doi.org/10.5860/ crln.70.5.8181

Budge, K., Lemon, N., \& McPherson, M. (2016). Academics who tweet: "Messy" identities in academia. Journal of Applied Research in Higher Education, 8(2), 210-221. https://doi.org/10.1108/JARHE-11-2014-0114 
Center for Engaged Learning. (n.d.). Home. YouTube. https://www.youtube. com/user/CELatElon/featured

Cohn, J., Stewart, M. K., Theisen, C. H., \& Comins, D. (2016). Creating online community: A response to the needs of 21 st century faculty development. Journal of Faculty Development, 30(2), 47-57.

Costley, J., \& Lange, C. (2017). The effects of lecture diversity on germane load. International Review of Research in Open and Distributed Learning, 18(2), 27-46.

Daniels, J. (2013, September 25). From tweet to blog post to peer-reviewed article: How to be a scholar now. LSE Impact Blog http://blogs.lse.ac.uk/ impactofsocialsciences/2013/09/25/how-to-be-a-scholar-daniels/

IUB CITL. (n.d.). Home. YouTube. https://www.youtube.com/channel/ UCklefcjemUpkM_oHkxFlfiw

IUB University Institutional Research and Reporting. (2017). Common data set. https://uir.sitehost.iu.edu/uirr/reports/compliance/cds/2017/IUBLA/A

Kaskie, B. (2017). The academy is aging in place: Assessing alternatives for modifying institutions of higher education. The Gerontologist, 57(5), 816823. https://doi.org/10.1093/geront/gnw001

Kern, B., Mettetal, G., Dixson, M. D., \& Morgan, R. K. (2015). The role of SoTL in the academy: Upon the 25th anniversary of Boyer's scholarship reconsidered. Journal of the Scholarship of Teaching and Learning, 15(3), 1-14. https://doi.org/10.14434/josotl.v15i3.13623

Macià, M., \& García, I. (2016). Informal online communities and networks as a source of teacher professional development: A review. Teaching and Teacher Education, 55, 291-307. https://doi.org/10.1016/j.tate.2016.01.021

Mackenzie, A., \& Martin, L. (2016). Developing digital scholarship: Emerging practices in academic libraries. American Library Association.

Mayer, R. E. (2009). Multimedia learning (2nd ed.). Cambridge University Press.

McKenna, A. F., Johnson, A. M., Yoder, B., Chavela Guerra, R. C., \& Pimmel, R. (2016). Evaluating virtual communities of practice for faculty development. Journal of Faculty Development, 30(1), 31-39.

McVeigh, J. (2011, April/May/June). Librarians, faculty and the Scholarship of Teaching and Learning. It's Academic: PaLA Bulletin, 13-16.

Meishar-Tal, H., \& Pieterse, E. (2017). Why do academics use academic social networking sites? International Review of Research in Open and Distributed Learning, 18(1), 1-22. https://files.eric.ed.gov/fulltext/EJ1136066. pdf

Nistor, N., Baltes, B., \& Schustek, M. (2012). Knowledge sharing and educational technology acceptance in online academic communities of practice. Campus-Wide Information Systems, 29(2), 108-116. https://doi.org/10| $.1108 / 10650741211212377$

To Improve the Academy • Vol. 39, No. 1 • Spring 2020 
Otto, P. (2014). Librarians, libraries, and the Scholarship of Teaching and Learning. New Directions for Teaching and Learning, 2014(139), 77-93. https:// doi.org/10.1002/tl.20106

Pataraia, N., Margaryan, A., Falconer, I., \& Littlejohn, A. (2015). How and what do academics learn through their personal networks. Journal of Further and Higher Education, 39(3), 336-357. https://doi.org/10.1080/03098 $77 \times .2013 .831041$

Rainie, L. (2011, July 13). The state of millennials [Presentation slides]. http:// www.pewinternet.org/2011/07/13/the-state-of-millennials-slides/

Rienties, B., \& Kinchin, I. (2014). Understanding (in)formal learning in an academic development programme: A social network perspective. Teaching and Teacher Education, 39, 123-135. https://doi.org/10.1016/j.tate.2014.01.004

Robinson, M. (2008). Digital nature and digital nurture: Libraries, learning and the digital native. Library Management, 29(1/2), 67-76. https://doi. org/10.1108/01435120810844658

Royal, K. D., Akers, K. S., Lybarger, M. A., \& Zakrajsek, T. D. (2014). Using social network analysis to evaluate research productivity and collaborations. Journal of Faculty Development, 28(1), 49-58.

Sorcinelli, M. D., Austin, A. E., Eddy, P. L., \& Beach, A. L. (2006). Creating the future of faculty development: Learning from the past, understanding the present. Anker Publishing.

Svinicki, M. D., \& McKeachie, W. J. (2014). McKeachie's teaching tips: Strategies, research, and theory for college and university teachers (14th ed.). Wadsworth.

Trust, T., Carpenter, J. P., \& Krutka, D. G. (2017). Moving beyond silos: Professional learning networks in higher education. The Internet and Higher Education, 35, 1-11. https://doi.org/10.1016/j.iheduc.2017.06.001

Van Rensburg, G. H., Botma, Y., Heyns, T., \& Coetzee, I. M. (2016). Establishing a community of practice: From outsiders to insiders. Gender \& Behaviour, 14(1), 7028-7039.

Van Waes, S., Van den Bossche, P., Moolenaar, N. M., De Maeyer, S., \& Van Petegem, P. (2015). Know-who? Linking faculty's networks to stages of instructional development. Higher Education, 70, 807-826. https://doi. org/10.1007/s10734-015-9868-8

Vogels, E. A. (2019, September 9). Millennials stand out for their technology use, but older generations also embrace digital life. Pew Research Center. https://www.pewresearch.org/fact-tank/2019/09/09/us-generationstechnology-use/

Williams, A. L., Verwoord, R., Beery, T. A., Dalton, H., McKinnon, J., Strickland, K., Pace, J., \& Poole, G. (2013). The power of social networks: A model for weaving the Scholarship of Teaching and Learning into institutional culture. Teaching \& Learning Inquiry: The ISSOTL Journal, 1(2), 49-62. 